Fernando Henrique Alves da Silva ${ }^{1 *}$ Selma Rogéria de Carvalho Nascimento ${ }^{1}$

Salvador Barros Torres ${ }^{1}$ Jessica Regiane de Oliveira ${ }^{1}$ Tatianne Raianne Costa Alves ${ }^{1}$ Andréia Mitsa Paiva Negreiros ${ }^{1}$

${ }^{1}$ Universidade Federal Rural do Semi-Árido UFERSA, Programa de Pós-graduação em Fitotecnia, BR-110, km 47, Costa e Silva, 59625-900, Mossoró, RN, Brasil

\section{*Autor Correspondente:}

E-mail: fernandosilvasr@hotmail.com

\section{PALAVRAS-CHAVE}

Vigna unguiculata

Callosobruchus maculatus

Fungo

Bactéria

Praga

\section{KEYWORDS}

Vigna unguiculata

Callosobruchus maculatus

Fungus

Bacteria

Pest

\section{Qualidade sanitária de sementes salvas de feijão-caupi utilizadas pelos agricultores do Rio Grande Norte}

\author{
Sanitary quality of saved seeds of Vigna unguiculata \\ used by farmers in Rio Grande do Norte
}

RESUMO: O objetivo deste trabalho foi verificar a qualidade sanitária de sementes salvas de feijão-caupi (Vigna unguiculata L. Walp.) coletadas no estado do Rio Grande do Norte. Para isso, 37 amostras de sementes salvas de feijão-caupi foram coletadas de diferentes municípios e comparadas com sementes básicas, variedades Guariba e Pujante, oriundas do campo de produção de sementes básicas da Embrapa Produtos e Mercado, Petrolina, PE. As sementes sem desinfestação foram plaqueadas em meio batata-dextrose-ágar e incubadas sob luz branca a $25 \pm 2{ }^{\circ} \mathrm{C}$, durante sete dias para posterior avaliação da incidência e frequência (\%) de fungos. A análise das sementes infestadas com pragas foi realizada através do corte longitudinal na semente observando a presença de orifício no tegumento, insetos, ovos e pupas. O delineamento utilizado foi o inteiramente casualizado, cujas médias foram comparadas pelo teste de Scott-Knott. Todas as amostras apresentaram incidência de microrganismos. Observou-se a frequência dos gêneros: Alternaria sp. (10\%), Aspergillus sp. (60\%), Bipolaris sp. (8\%), Colletotrichum sp. (5\%), Fusarium sp. (53\%), Macrophomina sp. (60\%), Penicillium sp. (13\%), Pleurophagminum sp. (5\%), Rhizopus sp. (73\%), Rhizoctonia sp. (70\%), Rhizobium sp. (100\%) e Pantoea sp. (3\%). O Callosobruchus maculatus Fabr. foi encontrado em $94 \%$ das amostras de sementes de feijão-caupi. As sementes salvas de feijão-caupi são inadequadas para semeadura e/ou comercialização, pois se constituem em agentes potencialmente disseminadores de pragas e patógenos.

ABSTRACT: The objective of this study was to investigate the sanitary quality of own or saved seeds of cowpea (Vigna unguiculata L. Walp.) collected in Rio Grande do Norte State, Brazil. For this, 37 saved seed samples were collected from different cities, which are compared to basic seed, and Guariba Pujante varieties derived from the basic seed production field of Embrapa Produtos e Mercado, Petrolina, PE. Seeds were plated without disinfestation on potato-dextrose agar and incubated under white light at $25 \pm 2{ }^{\circ} \mathrm{C}$ for seven days later to assess the incidence and frequency (\%) of fungi. The analysis of the seed infested with pests was carried out by slitting the seed observing the presence hole in the seed coat, insect eggs and pupae. The design was completely randomized, whose averages were compared by the Scott-Knott test. All samples showed an incidence of microorganisms. A frequency was observed of gender: Alternaria sp. (10\%), Aspergillus sp. (60\%), Bipolaris spp. (8\%), Colletotrichum sp. (5\%), Fusarium sp. (53\%), Macrophomina sp. (60\%), Penicillium sp. (13\%), Pleurophagminum sp. (5\%), Rhizopus sp. (73\%), Rhizoctonia sp. (70\%), Rhizobium sp. (100\%) and Pantoea sp. (3\%). The Callosobruchus maculatus Fabr. It was found in $94 \%$ of samples of cowpea seeds. Saved seeds are unsuitable for sowing and/ or marketing, because they are in potentially disseminating agents of pests and pathogens. 


\section{Introdução}

No Brasil, o feijão-caupi (Vigna unguiculata L. Walp.) é uma cultura que desempenha papel fundamental na produção agrícola por ser o principal componente na alimentação da população das regiões Norte e Nordeste. É uma cultura de ciclo curto, pouco exigente em fertilidade e que apresenta boa capacidade de fixar nitrogênio atmosférico, através da simbiose com bactérias do gênero Rhizobium, adaptando-se bem às condições climáticas com altas temperaturas (Bertini et al., 2009; Rego et al., 2015).

A falta de sementes certificadas no mercado limita o desempenho de qualquer sistema de produção. Independentemente da época escolhida, sementes salvas não obedecem aos padrões estabelecidos de produção de sementes, o que pode resultar em falhas na germinação, retardo a emergência de plântulas, disseminação de patógenos, dentre outros problemas (Lobo Júnior et al., 2013).

O comércio e a utilização de sementes salvas é uma realidade em países em desenvolvimento, neste sistema, mais de $80 \%$ dos agricultores estão envolvidos na seleção, produção, disseminação, vendas, trocas ou doações que ocorrem na comunidade local (Louwaars \& De Boef, 2012). Nesse sentido, o feijão-caupi pode sofrer perdas significativas de rendimento, proliferação de doenças de plantas, incluindo as que são transmitidas por sementes (Tozzo \& Peske, 2008).

A literatura tem evidenciado que as infecções ocasionadas por Aspergillus flavus, Macrophomina phaseolina, Fusarium oxysporum e Penicillium sp. são os principais responsáveis pela deterioração no armazenamento em sementes de feijão-caupi; esses agentes causam redução na germinação e são os principais responsáveis pela produção de micotoxinas prejudicial a saúde humana (Singh et al., 2007; Biemond et al., 2013).

A maioria dos patógenos sobrevive e se disseminam através de sementes, em geral, os fungos constituem os mais numerosos e importantes grupos de fitopatógenos associados às sementes, seguidos por bactérias, vírus, e alguns nematóides. Estes fitopatógenos causam em campo os danos mais frequentes, como abortos, deformações, apodrecimentos, manchas necróticas e descolorações, que ocasionam perda do poder germinativo da semente (Carvalho \& Nakagawa, 2012).

Além dos fungos, as bactérias também constituem o grupo de microrganismos patogênicos as sementes. Nos feijões Vigna unguiculata e Phaseolus vulgaris, por exemplo, as bacterioses causadoras de perdas são especialmente enquadradas nos gêneros Xanthomonas, Pseudomonas e Corynebacterium (Carvalho \& Nakagawa, 2012). Outras são encontradas como benéficas, como às bactérias promotoras de crescimento que podem ser de vida livre, associativas ou endofíticas. Estas são capazes de colonizar as raízes das plantas e, no caso das leguminosas, de coabitar com as bactérias fixadoras de nitrogênio dentro dos nódulos radiculares (Li et al., 2008). Podem, também, atuarem como solubilizadoras de fosfato, sendo considerada benéfica às sementes (Elvia et al., 2008).

A presença de pragas também compromete a qualidade sanitária das sementes, estas penetram nos grãos, ocasionando danos graves, como perda de peso, redução na germinação e valor nutricional do grão (Oke et al., 2013).
No âmbito da avaliação da qualidade de sementes, o teste de sanidade se faz necessário para definir o perfil da qualidade sanitária de um lote de sementes, conjuntamente a outros testes que indicam a qualidade fisiológica. Através desse teste, é possível identificar e prevenir a entrada de patógenos em áreas isentas, evitando futuros prejuízos devido ao aparecimento e desenvolvimento de doenças em campo, além de comparar a qualidade de diferentes lotes (Brasil, 2009a).

No tocante ao teste de sanidade, este tem como objetivo determinar o grau da ocorrência de microrganismos e insetos que causam doenças em plântulas e danos às sementes durante o armazenamento, ou que são transmitidos pela semente, sendo capazes de causar doenças e reduções na produtividade da cultura em campo (Brasil, 2009a).

Diante do exposto, o objetivo deste trabalho visou avaliar a qualidade sanitária de sementes salvas e comerciais de feijão-caupi utilizadas pelos produtores do estado do Rio Grande do Norte.

\section{Material e Métodos}

O experimento foi realizado no Laboratório de Microbiologia e Fitopatologia, pertencente ao Departamento de Ciências Vegetais (DCV) da Universidade Federal Rural do Semi-Árido (UFERSA), em Mossoró, RN, no período de janeiro de 2013 a agosto de 2014.

Para realização do experimento, foram utilizadas 40 amostras de sementes de feijão-caupi, sendo 37 de sementes salvas (utilizadas pelos produtores do Rio Grande Norte) e três amostras de sementes básicas, sendo uma da variedade BRS Pujante e duas da BRS Guariba, utilizadas como controle (referência de qualidade). As sementes salvas de feijão-caupi foram coletadas nos municípios de Angicos, Lajes, São Rafael, Caicó, São João do Sabugi, Timbaúba dos Batistas, Currais Novos, Bodó, Jandaíra, Apodi, Baraúna, Felipe Guerra, Mossoró, Severiano Melo, Alexandria, Luís Gomes, Pau dos Ferros, Portalegre, Rafael Fernandes, Venha-Ver, Campo Redondo, Santa Cruz, Tangará, Sítio Novo, São José do Campestre, Canguaretama, Lagoa de Pedras, Monte Alegre, Passagem, Várzea, Barcelona, Lagoa de Velhos, Ruy Barbosa, Santa Maria, Senador Éloi de Souza, Lucrécia e Umarizal, todos pertencentes ao estado do Rio Grande do Norte. As sementes básicas utilizadas como controle, foram provenientes da Embrapa Produtos e Mercado, Petrolina, PE, safra 2012/2013.

As amostras de sementes pesando em torno de $1,5 \mathrm{~kg}$ foram homogeneizadas (divisor tipo Gamet $($ ) para a retirada das amostras de trabalho (400 g). As sementes foram plaqueadas sem prévia desinfestação em placas de petri de $9 \mathrm{~cm}$ de diâmetro, contendo meio de cultura batata-dextrose-ágar (BDA). Estas foram distribuídas assepticamente, sendo dispostas equidistantes 10 sementes por placa. Cada amostra teve cinco repetições (cinco placas de Petri). As placas contendo as sementes foram colocadas em câmara de incubação do tipo Biochemical Oxygen Demand (B.O.D), sob luz fluorescente branca à temperatura de $25 \pm 2{ }^{\circ} \mathrm{C}$, durante sete dias. As análises iniciais foram realizadas a olho nu e contadas as colônias fúngicas e bacterianas desenvolvidas em volta e/ou sobre as sementes, com os resultados expressos em porcentagem. Posteriormente, as colônias fúngicas foram avaliadas ao microscópio óptico e identificadas, de acordo com 
o Manual de Análise Sanitária de Sementes (Brasil, 2009b) e chave de identificação de fungos (Barnett \& Hunter, 1998). As colônias bacterianas foram identificadas através de provas bioquímicas. Para a frequência e incidência de microrganismos utilizou-se as fórmulas propostas por Ghiasian et al. (2004):

$$
\mathrm{IF}=\frac{\mathrm{NS} \operatorname{com}(\mathrm{FB})}{\mathrm{TS}} x 100
$$

em que: $\mathrm{IF}=$ incidência de infecção (\%); NS com (FB) = número de sementes infectadas por fungo ou bactérias; $\mathrm{TS}=$ total de sementes;

$$
\mathrm{FI}=\frac{\mathrm{NA} \operatorname{com}(\mathrm{FB})}{\mathrm{TA}} \times 100
$$

em que: $\mathrm{FI}=$ frequência de infecção $(\%)$; NA com $(\mathrm{FB})=$ número de amostras que ocorreu fungo ou bactérias; $\mathrm{TA}=$ total de amostras.

Para o teste de sementes infestadas com pragas, empregou-se quatro repetições de 100 sementes por amostra, que foram imersas em água por 24 horas e posteriormente seccionadas e avaliadas uma a uma. Com auxílio do microscópio estereoscópio, verificou-se a presença de ovos, larvas, lagartas e insetos, bem como a presença de orifício de saída destes. O resultado foi expresso em percentagem de sementes infestadas, conforme recomendação das Regras para Análise de Sementes (Brasil, 2009b).

O delineamento estatístico foi o inteiramente casualizado, com cinco repetições. Os dados foram submetidos à análise de variância e as médias comparadas pelo teste de Scott-Knott em nível de $5 \%$ de probabilidade.

\section{Resultados e Discussão}

Na análise sanitária das sementes de feijão-caupi, verificou-se a presença de fungos fitopatogênicos e de armazenamento, bactérias e pragas. Os fungos foram os microrganismos de maior diversidade presentes nas amostras, seguido das bactérias e pragas.

Os fungos fitopatogênicos variaram com a frequência de $5 \%$ (Colletotrichum sp.) a 70\% (Rhizoctonia sp.) e os de armazenamento de 13\% (Penicillium sp.) a 73\% (Rhizopus sp.). Estes microrganismos foram os de maior diversidade, tendo sido encontrados 10 gêneros nas amostras avaliadas. Dentre os fungos identificados de maior frequência em ordem decrescente estão: Rhizopus sp., Rhizoctonia sp., Macrophomina phaseolina, Aspergillus sp. e Fusarium sp. (Tabela 1). A ocorrência de Rhizopus sp., Aspergillus sp. e Penicillium sp. sobre sementes de feijão-caupi também foi relatada em estudos realizados por Houssou et al. (2009).

Em média, menos gêneros de patógenos foram identificados nas amostras de sementes comerciais. Nestas, observou-se a presença de cinco gêneros de patógenos; sendo três considerados saprófitas e dois fitopatogênicos. Em relação às sementes salvas, estas apresentaram dez gêneros entre saprófitas e fitopatogênicos. Este resultado foi confirmado também por Biemond et al. (2013) em que o numero de gêneros patogênicos foi reduzido com a utilização de sementes comerciais de feijão-caupi. Desta maneira, pode-se afirmar que a utilização de sementes comerciais é mais segura em evitar a proliferação de patógenos veiculados por sementes.

As amostras que apresentaram maior incidência de Aspergillus sp. foram as oriundas dos municípios de Lucrécia (54\%) e Apodi (38\%). As amostras com menor incidência foram as provenientes de Lagoa de Velhos, Passagem, Timbaúba dos Batistas e a amostra controle da variedade Pujante, ambas com $2 \%$ de incidência desse fungo. As demais amostras apresentaram incidência fúngica variando de 4 a $38 \%$ (Tabela 1).

A ocorrência do fungo Penicillium $\mathrm{sp}$. ficou restrita a cinco amostras do total de 40. A amostra que apresentou maior incidência $(12 \%)$ foi a do município de Umarizal, enquanto que as amostras oriundas de Monte Alegre e Ruy Barbosa tiveram menor incidência (2\%). As amostras de Lagoa de Pedras e da variedade Pujante apresentaram, também, 4\% de incidência de Penicillium sp. (Tabela 1). Este resultado corrobora ao encontrado por Biemond et al. (2013), também com sementes de feijão-caupi, cujos autores verificaram a presença do fungo Penicillium sp. na safra 2010 com incidência de 12,6\%.

Os fungos de armazenamento como Aspergillus sp. e Penicillium sp. podem ser altamente prejudiciais às sementes, podendo reduzir a germinação e causar a morte do embrião, bem como o apodrecimento da semente, aquecimento da massa com a aceleração da taxa respiratória e, consequente, deterioração destas, além de atuarem na produção de micotoxinas, algumas sendo letais ao homem e aos animais, como a aflatoxina (Carvalho \& Nakagawa, 2012).

Outros fungos apresentaram menor frequência como Bipolaris sp. e Pleurophragmium sp. (Tabela 1). Bipolaris sp. é comumente encontrado em sementes de várias espécies, principalmente de gramíneas (Kobayasti \& Pires, 2011) e o Pleurophragmium sp. é considerado como fungo decompositor e saprófita, podendo estar presente em vegetais já em decomposição (D’Souza \& Bhat, 2012).

Os fungos considerados fitopatogênicos presentes nas amostras de sementes foram Macrophomina phaseolina, Fusarium sp., Rhizoctonia sp., Colletotrichum sp. e Alternaria sp. Entre estes, a Rhizoctonia sp. apresentou maior frequência, seguido por Macrophomina phaseolina e Fusarium sp.

Para o fungo Alternaria sp., houve $10 \%$ de frequência e para o Colletotrichum sp. 5\%. Das 40 amostras avaliadas, 15 não apresentaram incidência de Rhizoctonia sp., 13 não tinham M. phaseolina e 18 não continham Fusarium sp. Apenas uma amostra, a do município de Passagem, apresentou ocorrência de Colletotrichum sp. (Tabela 1). Alguns autores, também, relataram a presença destes fungos nos levantamentos sanitários em sementes de feijão-caupi (Ikran \& Dawar, 2013; Ito et al., 2013). O Colletotrichum sp., agente causal da antracnose e, a Alternaria sp., agente causal da doença denominada mancha de alternaria, ambos são fungos encontrados, também, em outros estudos como os realizados por Biemond et al. (2013).

A frequência de Macrophomina phaseolina foi observada em $60 \%$ das amostras coletadas. Não foi observada a presença deste fungo nas sementes produzidas de forma comercial. Macrophomina phaseolina é considerado um fungo habitante do solo que ataca dentre outras plantas o feijão-caupi, causando danos às sementes, raízes e colo da planta (Ikram \& Dawar, 2013; Biemond et al., 2013). 
Tabela 1. Qualidade sanitária de sementes básicas de feijão-caupi (Vigna unguiculata L. Walp.) comparadas com 37 amostras da mesma espécie, coletadas em diferentes municípios do Rio Grande do Norte.

Table 1. Sanitary quality of basic seeds of cowpea (Vigna unguiculata L. Walp.) Compared to 37 samples of the same species, collected in different municipalities of Rio Grande do Norte.

Incidência de fungos e bactérias (\%)

\begin{tabular}{|c|c|c|c|c|c|c|c|c|c|c|c|c|c|}
\hline Amostras & 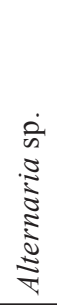 & 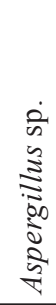 & 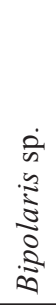 & 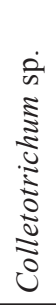 & 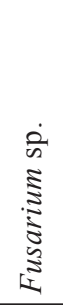 & 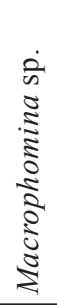 & 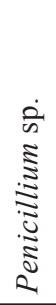 & 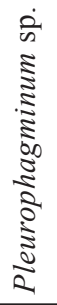 & 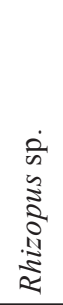 & 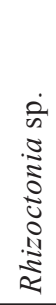 & 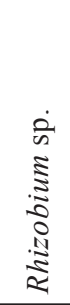 & 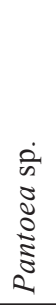 & Pragas (\%) \\
\hline Guariba I* & & 18 & & & 6 & & & & 2 & 4 & 38 & & $0,00 \mathrm{e}$ \\
\hline Guariba II* & & & & & & & & & 4 & & 82 & & $0,00 \mathrm{e}$ \\
\hline Pujante* & & 2 & & & 6 & & 4 & & 2 & 4 & 34 & & $0,00 \mathrm{e}$ \\
\hline Alexandria & & & & & & 16 & & & 10 & & 12 & & $10,50 \mathrm{~d}$ \\
\hline Angicos & & 14 & & & & 4 & & & 4 & 2 & 20 & & $35,00 \mathrm{a}$ \\
\hline Apodi & & 38 & & & & & & & & 2 & 32 & & $3,50 \mathrm{e}$ \\
\hline Baraúna & & 6 & & & & & & & 10 & & 10 & & $2,50 \mathrm{e}$ \\
\hline Barcelona & & 14 & & & 2 & 10 & & & 2 & & 32 & & $0,00 \mathrm{e}$ \\
\hline Bodó & & & & & 13 & & & & & & 56 & & $0,00 \mathrm{e}$ \\
\hline Caicó & & & & & 2 & 6 & & & 4 & 4 & 4 & 2 & $21,00 \mathrm{~b}$ \\
\hline Campo Redondo & & & & & 4 & 2 & & & 14 & 8 & 6 & & $14,00 \mathrm{c}$ \\
\hline Canguaretama & & & & & 16 & 2 & & & 6 & 10 & 10 & & $5,50 \mathrm{~d}$ \\
\hline Currais Novos & & 6 & & & & & & & 8 & & 68 & & $5,00 \mathrm{~d}$ \\
\hline Felipe Guerra & & 32 & & & & 6 & & & 2 & 16 & 2 & & $2,00 \mathrm{e}$ \\
\hline Jandaíra & & 4 & & & & & & & 8 & & 52 & & $15,00 \mathrm{c}$ \\
\hline Lagoa de Pedras & & 4 & & & 8 & 2 & 4 & & 4 & 10 & 30 & & $26,00 \mathrm{~b}$ \\
\hline Lagoa de Velhos & 2 & 2 & 2 & & 4 & & & & & & 56 & & $6,00 \mathrm{~d}$ \\
\hline Lajes & & 6 & & & & 4 & & & 2 & 4 & 11 & & $0,50 \mathrm{e}$ \\
\hline Lucrécia & & 54 & & & 6 & & & & 6 & & 34 & & $1,50 \mathrm{e}$ \\
\hline Luiz Gomes & & & & & & 38 & & & 4 & 2 & 50 & & $1,00 \mathrm{e}$ \\
\hline Monte Alegre & & 8 & & & & & 2 & 2 & 4 & 2 & 80 & & $11,00 \mathrm{c}$ \\
\hline Mossoró & & & & & 4 & 6 & & & 2 & 8 & 12 & & $16,00 \mathrm{c}$ \\
\hline Passagem & & 2 & & 2 & 4 & 18 & & & & 2 & 36 & & $1,00 \mathrm{e}$ \\
\hline Pau dos Ferros & 10 & 10 & & & 18 & & & & & 22 & 24 & & $2,50 \mathrm{e}$ \\
\hline Portalegre & & & & & & 38 & & & 8 & 4 & 10 & & $10,00 \mathrm{~d}$ \\
\hline Rafael Fernandes & & & & & 4 & 30 & & & 2 & 28 & 6 & & $14,00 \mathrm{c}$ \\
\hline Ruy Barbosa & & 6 & & & & 6 & 2 & & & 18 & 66 & & $1,50 \mathrm{e}$ \\
\hline Santa Cruz & & & & & 2 & & & & 8 & 4 & 30 & & $3,50 \mathrm{e}$ \\
\hline Santa Maria & & & & & & 14 & & & & 36 & 16 & & $8,50 \mathrm{~d}$ \\
\hline São João do Sabugi & & 10 & & & & 16 & & & 8 & 2 & 4 & & $26,00 \mathrm{~b}$ \\
\hline São José do Campestre & & & & & 26 & 2 & & & 4 & 10 & 32 & & $0,50 \mathrm{e}$ \\
\hline São Rafael & & 4 & 2 & & & 12 & & & 6 & 20 & 6 & & $6,00 \mathrm{~d}$ \\
\hline Senador Elói de Souza & & & & & 10 & 8 & & & 2 & 30 & 2 & & $21,50 \mathrm{~b}$ \\
\hline Severiano Melo & & 30 & & & & 2 & & & 2 & & 82 & & $12,00 \mathrm{c}$ \\
\hline Sítio Novo & & & & & 22 & & & & 12 & 8 & 6 & & $12,50 \mathrm{c}$ \\
\hline Tangará & & 4 & & & 20 & & & & 2 & 8 & 4 & & $5,00 \mathrm{~d}$ \\
\hline Timbaúba dos Batistas & & 2 & & & & 12 & & & 6 & 22 & 4 & & $6,00 \mathrm{~d}$ \\
\hline Umarizal & & 10 & & & & 4 & 12 & & & 10 & 4 & & $0,50 \mathrm{e}$ \\
\hline Várzea & & & & & 2 & 2 & & & & & 40 & & $5,50 \mathrm{~d}$ \\
\hline Venha-Ver & 2 & 28 & & & 2 & & & 6 & & 4 & 16 & & $9,00 \mathrm{~d}$ \\
\hline Frequência (\%) & 10 & 60 & 8 & 5 & 53 & 60 & 13 & 5 & 73 & 70 & 100 & 3 & \\
\hline CV (\%) & & & & & & & & & & & & & 39,89 \\
\hline
\end{tabular}

*Amostra controle de semente básica. **Médias seguidas de mesmas letras nas colunas não diferem estatisticamente entre si pelo teste de Scott-Knott ao nível de $5 \%$ de probabilidade. 
A presença de Fusarium sp. foi detectado em trabalhos com sementes de feijão-caupi, desenvolvido por Houssou et al. (2009) e Biemond et al. (2013). Estes últimos, verificaram a presença de três espécies de Fusarium sp. (F. oxysporum, $F$. verticillioides e $F$. solani), causando inibição na germinação das sementes, ataque de plântulas e necrose nas radículas.

A maioria dos agentes etiológicos das doenças do feijão-caupi são disseminados e transmitidos via semente, principalmente as causadas por fungos, estabelecendo-se assim possíveis focos primários de infecção em novas áreas de cultivo (Machado, 1994).

O uso de sementes infectadas ou contaminadas, além dos fatores negativos referentes à disseminação e transmissão de patógenos as plantas oriundas da germinação, podem também contaminar outras plantas na mesma lavoura, causando perdas no rendimento da cultura (Ito et al., 2013).

Os fungos fitopatogênicos atacam as sementes de feijão-caupi proliferando doenças em plântulas prejudicando o desenvolvimento (Biemond et al., 2013). Os principais sintomas são: damping-off, podridão de raízes e colo com consequente sintomas indiretos de deficiência nutricional, como necrose nas folhas, amarelecimento, murcha e morte das plantas, podem ser causados por fungos como a Macrophomina phaseolina, Rhizoctonia solani e Fusarium solani (Ikram \& Dawar, 2013).

Nas análises sanitárias das amostras de sementes de feijão-caupi foram encontradas bactérias em $100 \%$ das amostras examinadas, e dentre os gêneros, o Rhizobium sp. foi a de maior frequência (100\%). As bactérias do gênero Rhizobium sp. são simbióticas de plantas leguminosas, realizam fixação biológica de nitrogênio e apresentam papel fundamental no aumento de produção de feijão-caupi (Silva Junior et al., 2014). Pois sua presença nas sementes constitui-se em indício benéfico para as plantas oriundas de sua germinação.

A bactéria Pantoea sp. teve frequência menor que 3\%, aparecendo exclusivamente na amostra proveniente do município de Caicó, com incidência de 2\% (Tabela 1). A presença de bactérias endofíticas não simbióticas vem sendo relatado em nódulos de plantas leguminosas (Costa et al., 2013). A bactéria Pantoea sp. é considerada promotora de crescimento pode ter vida livra associativas ou endofíticas, como no caso das amostras do presente estudo. São capazes de colonizar as raízes das plantas e, no caso das leguminosas, de coabitar com as bactérias fixadoras de nitrogênio dentro dos nódulos radiculares (Li et al., 2008), ou atuarem como solubilizadoras de fosfato (Elvia et al., 2008), sendo benéfica sua presença nas sementes.

Das diversas pragas que atacam as sementes durante o armazenamento, o gorgulho do feijoeiro (Callosobruchus maculatus Fabr.) foi à única espécie verificada neste estudo. A porcentagem de sementes com a presença deste inseto oscilou de zero, para as amostras provenientes dos municípios de Barcelona e Bodó, a 35\%, para as amostras provenientes de Angicos. Das 37 amostras avaliadas, 94\% apresentaram-se contaminadas com esse inseto, sendo que $68 \%$ destas estavam improprias para a comercialização, segundo os critérios estabelecidos pela Instrução Normativa de número 45, de 17 de setembro de 2013 (Abrasem, 2015). As amostras controle, representadas pelas variedades Pujante e Guariba I e II apresentaram-se livres dessa praga (Tabela 1). Segundo Oke et al. (2013) a presença do Callosobruchus maculatus nas sementes de feijão-caupi causa grandes prejuízos na redução dos valores nutricionais, peso das sementes, ácidos graxos e outras variáveis nutricionais importante. De acordo com Pascual-Villalobo \& Ballesta-Acosta (2003) nas regiões Norte e Nordeste do Brasil, 90\% dos danos provocados por insetos às sementes de feijão-caupi são causados pelo Callosobruchus maculatus. Segundo ainda os mesmos autores, esse inseto provoca perfurações nas sementes ou grãos, podendo chegar, dentro de três a quatro meses de armazenamento, a $50 \%$ de infestação nas sementes, principalmente em casos de armazenagem inadequada.

\section{Conclusões}

As sementes comerciais de feijão-caupi, produzidas de acordo com as recomendações técnicas de produção, apresentam atributos sanitários superiores às sementes salvas. As sementes salvas de feijão-caupi são inadequadas para semeadura e/ou comercialização, pois se constituem em agentes potencialmente disseminadores de pragas e doenças.

\section{Referências}

ABRASEM. Associação Brasileira de Sementes e Mudas. Disponível<http://www.abrasem.com.br/wpcontent/uploads/2012/10/ Instru\%C3\%A7\%C3\%A3o-Normativa-n \%C2\%BA-45-de-17-deSetembro-de-2013-Padr\%C3\%B5es-de-Identidade-e-Qualiidade-Prod-eComerc-de-Sementes-Grandes-Culturas-Republica $\% \mathrm{C} 3 \% \mathrm{~A} 7 \% \mathrm{C} 3 \% \mathrm{~A} 30-$ DOU-20.09.13.pdf> Acesso em 10 de fevereiro de 2015.

BARNETT, H .L.; B. B. HUNTER. Illustrated genera of imperfect fungi. 4. ed. St. Paul, MN: Am. Phytopatol. Soc. Press, 1998. 218 p.

BERTINI, C. H. C. M.; TEÓFILO, E. M.; DIAS, F. T. C. Divergência genética entre acessos de feijão caupi do banco de germoplasma da UFC. Revista Ciência Agronômica, v. 40, n. 1, p. 99-105, 2009.

BIEMOND, P. C.; OGUNTADE, O.; KUMAR, P. L.; STOMPH, T. J.; TERMORSHUIZEN, A. J.; STRUIK, P. C. Does the informal seed system threaten cowpea seed health?. Crop Protection, v. 43, p. 166-174, 2013. http://dx.doi.org/10.1016/j.cropro.2012.09.007

BRASIL. Ministério da Agricultura, Pecuária e Abastecimento. Manual de análise sanitária de sementes. Brasília: MAPA/ACS, 2009b. 200 p.

BRASIL. Ministério da Agricultura, Pecuária e Abastecimento. Regras para análise de sementes. Brasília: MAPA/ACS, 2009a. 399 p.

CARVALHO, N. M.; NAKAGAWA, J. Sementes: ciência, tecnologia e produção. 5. ed. Jaboticabal: Funep, 2012. 590 p.

COSTA, E. M.; NÓBREGA, R. S. A.; CARVALHO, F.; TROCHMANN, A.; FERREIRA, L. V. M. MOREIRA, F. M. S. Promoção do crescimento vegetal e diversidade genética de bactérias isoladas de nódulos de feijão-caupi. Pesquisa. Agropecuária Brasileira, v. 48, n. 9, p. $1275-$ 1284, 2013. http://dx.doi.org/10.1590/S0100-204X2013000900012.

D' SOUZA; M.; BHAT, D. J. A new species of Pleurophragmium from India. Micotaxon, v. 119, n. 6, p. 477-482, 2012. http://dx.doi. org/10.5248/119.477

ELVIA, J. C.; ORTEGA-RODÉS P.; ORTEGA E. La inoculación de plantas de Pantoea sp., bacteria solubilizadora de fosfatos, incrementa la concentración de $\mathrm{P}$ en los tejidos foliares. Revista Colombiana de Biotecnologia, v. 10, n. 1, p. 111-21, 2008. 
GHIASIAN, S. A.; KORD-BACHEH, P.; REZAYAT, S. M.; MAGHSOOD, A. H.; TAHERKHANI, H. Mycoflora of Iranian maize harvested in the main production areas in 2000. Mycopathologia, v. 158, n. 1, p. 113 121, 2004. DOI: 10.1023/B:MYCO.0000038425.95049.03.

HOUSSOU, P. A., AHOHUENDO, B. C., FANDOHAN, P., KPODO, K., HOUNHOUIGAN, D. J., JAKOBSEN, M. Natural infection of cowpea (Vigna unguiculata (L.) Walp.) by toxigenic fungi and mycotoxin contamination in Benin, West Africa. Journal of Stored Products Research, v. 45, n. 1, p. 40-44, 2009. http://dx.doi.org/10.1016/j. jspr.2008.07.002.

IKRAM, N.; DAWAR, S. Effect of Prosopis juliflora (Sw.) DC. in the control of root rot fungi of cowpea (Vigna unguiculata L. Walp.) and mung bean (Vigna radiata L. Wilczek). Pakistan Journal of Botany, v. 45, n. 2, p. 649-654, 2013.

ITO, M. F.; COSTA, A. F.; PIRES, B. E.; CANUTO, V. T. B.; OLIVEIRA, L. G.; SOUZA, M.C.M. Sanidade de sementes de feijão-caupi. In: III CONAC Congresso Nacional de Feijão-caupi, Recife - PE, 2013 http://www.conac2012.org/resumos/pdf/134a.pdf.

KOBAYASTI, L.; PIRES, A. P. Levantamento de fungos em sementes de trigo. Pesquisa Agropecuária Tropical, v. 41, n. 4, p. 572-578, 2011.

LI, J. H.; WANG, E. T.; CHEN, W. F.; CHEN, W. X. Genetic diversity and potential for promotion of plant growth detected in nodule endophytic bacteria of soybean grown in Heilongjiang province of China. Soil Biology \& Biochemistry, v. 40, p. 238-246, 2008. DOI: 10.1016/j.soilbio.2007.08.014.

LOBO JÚNIOR, M.; BRANDÃO, L. T. D.; MARTINS, B. E. DE M. Testes para avaliação da qualidade de sementes de feijão comum. Santo Antônio de Goiás: Embrapa Arroz e Feijão, 2013. 4 p. (Embrapa Arroz e Feijão, Circular Técnica, 90).

LOUWAARS, N. P.; DE BOEF, W. S. Integrated seed sector development in Africa: a conceptual framework for creating coherence between practices, programs, and policies. Journal of Crop Improvement, v. 26, n. 1, p. 39-59, 2012. DOI:10.1080/15427528.2011.611277.
MACHADO, J. C. Padrões de tolerância de patógenos associados às sementes. Revisão Anual de Patologia de Plantas, v. 2, p. $229-$ 262,1994

OKE, O. A.; AKINTUNDE, E. M.; IJAOLA, S.; RAJI, D.; AGBON, $J$. Reduction of the nutritional values of cowpea infested with Callosobruchus maculatus (Coleoptera: Bruchidae). International Journal of current Microbiology and Applied Sciences, v. 3, n. 1, p. 30-36, 2013.

PASCUAL-VILlAlOBOS, M. J.; BALlESTA COSTA, M. C. Chemical variation in an Ocimum basilicum germplasm collection and activity of the essential oils on Callosobruchus maculatus. Biochemical Systematics and Ecology, v. 31, n. 7, p. 673-679, 2003. DOI: 10.1016/S0305-1978(02)00183-7.

REGO, F. A.; DIOP, I.; SADIO, O.; SYLVA, M. C.; AGBANGBA, C. E.; TOURÉ, O.; KANE, ABOUBACRY.; NEYRA, M.; NDOYE I.; WADE, T. K. Response of cowpea to symbiotic microorganisms inoculation (Arbuscular mycorrhizal fungi and Rhizobium) in cultivated soils in Senegal. Universal Journal of Plant Science, v. 3, n. 2, p. 32-42, 2015. DOI: 10.13189/ujps.2015.030204.

SILVA JÚNIOR, E. B.; SILVA, K.; OLIVEIRA, S. S.; OLIVEIRA, P. J.; BODDEY, R. M.; ZILLI, J. E.; XAVIER, G. R. Nodulação e produção de feijão-caupi em resposta à inoculação com diferentes densidades rizobianas. Pesquisa Agropecuária Brasileira, v. 49, n. 10, p. 804-812, 2014. DOI: 10.1590/S0100-204X2014001000007.

SINGH, N. D.; SHARMA, A. K., DWIVEDI, P.; PATIL, R. D.; KUMAR, M. Citrinin and endosulfan induced teratogenic effects in Wistar rats: Pathomorphological study. Journal of Applied Toxicology, v. 27, n. 2, p. 143-151, 2007. DOI: 10.1002/jat.1242.

TOZZO, G. A.; PESKE, S. T. Morphological characterization of fruits, seeds and seedlings of Pseudima frutescens (aubl.) radlk. (Sapindaceae). Revista Brasileira de Sementes, v. 30, n. 2, p. 12-18, 2008. http://dx.doi.org/10.1590/S0101-31222008000200002.

Contribuição dos autores: Fernando Henrique, Jéssica Regiane e Selma Rogéria realizaram o experimento; Tatianne Raianne e Salvador Torres contribuíram com a revisão bibliográfica; Andreia Mitsa e Fernando Henrique contribuíram com a escrita científica e Salvador Torres com a revisão ortográfica e gramatical do trabalho.

Fonte de financiamento: Não houve fonte de financiamento.

Conflito de interesse: Os autores declaram não haver conflito de interesse. 